\title{
Justificando Generalizações Geométricas na Formação Inicial de Professores dos Primeiros Anos
}

\author{
Justifying Geometrical Generalizations in Elementary School Preservice \\ Teacher Education
}

\author{
Lina Brunheira* \\ ORCID iD 0000-0002-5027-1867 \\ João Pedro da Ponte ${ }^{* *}$ \\ ORCID iD 0000-0001-6203-7616
}

\begin{abstract}
Resumo
Este artigo enquadra-se numa experiência de formação com futuras professoras e educadoras do $2^{\circ}$ ano de uma Licenciatura em Educação Básica, desenvolvida em Portugal, em que estas produziram justificações de generalizações num contexto de ensino exploratório. $\mathrm{O}$ estudo tem como objetivo compreender a forma como justificam generalizações sobre famílias de figuras geométricas. Os dados foram recolhidos por registros de áudio e vídeo e das produções escritas das formandas, focando-se nos argumentos usados para justificar generalizações sobre famílias de figuras. Na análise, mereceu especial atenção o tipo de argumentos, o seu grau de generalidade, as dificuldades manifestadas e os aspectos que promoveram a aprendizagem deste processo. Os resultados mostram que as formandas revelam algumas dificuldades em construir justificações, em parte pela incompreensão da natureza da justificação. Inicialmente manifestam dificuldades com o objeto de estudo (uma família de figuras em vez de uma figura única), e dificuldades na explicitação completa de argumentos e o seu discurso assenta, sobretudo, em casos particulares. A associação da justificação ao investigar o porquê da generalização, bem como a natureza e o desenho cuidadoso da tarefa e a interação na sala de aula podem potenciar a melhoria das justificações.
\end{abstract}

Palavras-chave: Geometria. Raciocínio. Justificação. Generalização. Formação Inicial.

\begin{abstract}
This article is part of a teacher education experience implemented in Portugal with future teachers and educators of the $2^{\text {nd }}$ year of a basic education degree, in which they have produced evidence of justifications of generalizations in a context of exploratory teaching. The study aims to understand how they justify generalizations about families of geometric figures. Data were collected by audio and video records and from the participants' written productions, focusing on arguments used to justify generalizations about families of figures. In the analysis, special attention was given to the kind of arguments, its generality degree, the difficulties expressed and the aspects that have promoted the learning of this process. The results show that the participants had some difficulties in building justifications, in part by the lack of understanding about the justification nature.

\footnotetext{
${ }^{*}$ Mestre em Educação (especialidade Didática da Matemática) pela Faculdade de Ciências da Universidade de Lisboa (FCUL). Professora na Escola Superior de Educação de Lisboa (ESELX), Lisboa, Portugal. Endereço para correspondência: Campus de Benfica do Instituto Politécnico de Lisboa, Lisboa, Portugal, C.P: 1549-003. E-mail: lbrunheira@eselx.ipl.pt.

** Doutor em Educação Matemática pela Universidade da Georgia. EUA (UGA). Professor catedrático do Instituto de Educação, Universidade de Lisboa (IE-ULisboa), Lisboa, Portugal. Endereço para correspondência: Alameda dfa Universidade, Lisboa, Portugal, C.P: 1649-013. Email: jpponte@ ie.ulisboa.pt.
} 
Initially, they expressed difficulties with the study object (a family of figures instead of a unique figure) and difficulties in fully providing arguments and their discourse was mainly based on specific cases. The association of justification to investigate the generalization, as well as the nature and the careful task design and classroom interaction may promote the improvement of justifications.

Keywords: Geometry. Reasoning. Justification. Generalization. Preservcice Teachers Education.

\section{Introdução}

Nas últimas duas décadas tem havido um interesse crescente no raciocínio matemático que pode ser observado em documentos de orientação curricular como os Princípios e normas da matemática escolar (NCTM, 2007), no qual se elege o raciocínio como uma das normas de processo centrais na experiência matemática desde a educação pré-escolar. Em Portugal, também o raciocínio matemático mereceu um especial destaque no Programa de Matemática do Ensino Básico (PONTE et al., 2007, p. 8), como uma capacidade transversal que "envolve a construção de cadeias argumentativas que começam pela simples justificação de passos e operações na resolução de uma tarefa e evoluem progressivamente para argumentações mais complexas", devendo merecer uma grande atenção em todos os ciclos de ensino.

Também a investigação em Educação Matemática tem acompanhado o interesse sobre o raciocínio, especialmente no que diz respeito à argumentação e demonstração (HANNA, 2000; STYLIANIDES, 2007). Do ponto de vista dos temas matemáticos e níveis de escolaridade, como referem Stylianides, Bieda e Morselli (2016), a geometria continua a ser o campo mais profícuo para a investigação, particularmente no ensino secundário. Entre as linhas de investigação identificadas na última década, surgiram estudos centrados na sala de aula e que procuram encontrar formas de apoiar os alunos na argumentação e demonstração. Estes autores consideram que esta área se beneficiaria com investigação que desenhasse ferramentas práticas, para utilização em sala de aula, baseadas em ideias teóricas. Já na área da formação de professores, consideram que o foco da investigação mantém a incidência na natureza do conhecimento sobre argumentação e prova sugerindo que

é necessário mais investigação sobre o desenvolvimento do conhecimento matemático dos professores sobre argumentação e demonstração, com o desenho de intervenções que tenham explicitamente em conta a ideia de que um ensino eficaz de matemática requer que os professores tenham não apenas um bom conhecimento de matemática, mas sejam também capazes de usar flexivelmente esse conhecimento para apoiar a aprendizagem dos seus alunos (STYLIANIDES; BIEDA; MORSELLI, 2016, p. 342).

O trabalho aqui apresentado surge justamente da necessidade sentida pela primeira autora, enquanto professora, em apoiar os futuros professores no seu raciocínio matemático, particularmente no que diz respeito ao processo de justificação em geometria. O seu objetivo 
é compreender a forma como justificam generalizações sobre famílias de figuras geométricas, analisando as seguintes questões: Que tipo de argumentos usam os futuros professores para justificar generalizações sobre famílias de figuras geométricas? Que dificuldades manifestam? Que atividades promovem o saber justificar e compreender a natureza da justificação?

\section{Raciocínio matemático e justificação}

Ponte, Mata-Pereira e Henriques (2012) indicam que dois processos de raciocínio centrais são a generalização, no qual sobressaem os aspectos indutivos, e a justificação, no qual sobressaem os dedutivos. Numa perspectiva semelhante, Lannin, Ellis e Elliot (2011) afirmam que o raciocínio matemático é um processo evolutivo que inclui conjecturar, generalizar, investigar porquê, justificar e refutar. No que se refere à generalização, existem dois tipos de atividades: identificar pontos comuns em casos diferentes e estender uma afirmação além do domínio em que foi originada. Investigar porquê envolve a identificação de relações que permitem perceber por que uma afirmação é verdadeira ou falsa. Os autores entendem uma justificação válida como uma sequência lógica de afirmações, cada uma apoiando-se em conhecimento já estabelecido, de forma a chegar a uma conclusão. Este tipo de justificação deve conter linguagem geral que demonstre que se aplica a mais do que um caso particular, sem prejuízo de se poderem usar exemplos, mas que devem constituir exemplos genéricos. Esta definição de justificação inclui a redução ao absurdo, em que uma afirmação fica validada pelo fato de a sua negação ser falsa, que é muitas vezes a única razão que permite estabelecer que a afirmação é verdadeira. Contudo, em termos gerais, os autores consideram que, no âmbito do ensino, investigar porquê está intrinsecamente associado ao processo de justificar, na medida que "os alunos constroem justificações para se convencerem a si próprios e aos outros porque é que uma afirmação particular é verdadeira" (p. 35).

Esta visão da justificação inclui os papéis de validação e de compreensão de resultados e uma dimensão comunicativa que busca a legitimidade da atividade matemática - aspectos que associamos à demonstração. Na verdade, os conceitos de justificação e demonstração são muito próximos, o que deriva de a demonstração assumir vários significados, quer no âmbito da investigação em Educação Matemática (STYLIANIDES; BIEDA; MORSELLI, 2016), quer em Matemática, já que existem opiniões diversas sobre o seu papel e o que a torna aceitável (HANNA, 2000; HAREL; SOWDER, 2007).

Tradicionalmente, o termo demonstração aparece associado a um elevado grau de formalismo e de complexidade próprios do ensino secundário ou superior, uma perspectiva 
contrariada por alguns autores que propõem um significado mais abrangente, embora nem sempre claro, para o termo demonstração. Por exemplo, Harel e Sowder (2007) assumem o caráter subjetivo (itálico dos autores) da sua perspectiva, segundo a qual uma demonstração é aquilo que estabelece a verdade para uma pessoa ou uma comunidade, podendo permear todo o currículo de Matemática, começando pelo jardim de infância. Tendo em vista conceituar a demonstração, tendo também em conta os primeiros anos de escolaridade, Stylianides (2007) propõe uma definição fundada na literatura sobre filosofia da Matemática e Educação Matemática:

Uma demonstração é um argumento matemático, uma sequência de afirmações interligadas, a favor ou contra uma afirmação matemática, com as seguintes características: 1. Usa afirmações aceites na comunidade da sala de aula (um conjunto de afirmações aceites) que são verdadeiras e disponíveis sem justificação adicional; 2. Emprega formas de raciocínio (modos de argumentação) que são válidas e conhecidas, ou ao alcance conceptual, da comunidade de sala de aula; e 3. É comunicada usando formas de expressão (modos de representação de argumentos) que são apropriadas e conhecidas, ou ao alcance conceptual, da comunidade de sala de aula (p. 291).

Neste estudo utilizamos o termo "justificação" com o significado aqui atribuído por Stylianides à "demonstração"1, de maneira a incluir formas de argumentação com diferentes graus de formalidade e referentes a vários níveis de escolaridade.

\section{Formação de professores e o processo de justificar}

Lo e McCrory (2009) defendem que os futuros professores dos primeiros anos devem aprender a justificar e sobre justificação a três níveis: a) enquanto ferramenta para mostrar ou verificar a verdade de uma afirmação; b) enquanto objeto matemático que se regula por regras e padrões, tais como tornar os passos explícitos, basear-se em premissas e assumir caraterísticas ajustadas à respetiva comunidade; e c) enquanto fator de desenvolvimento dos alunos, dependente do seu nível de ensino, do conhecimento matemático que podem mobilizar, do tipo de argumentos que são capazes de formular e das representações que podem usar. Estes três níveis correspondem ao que as autoras indicam como saber justificar, compreender a natureza da justificação e adaptar a justificação ao nível de desenvolvimento dos alunos, sendo os dois primeiros associados ao conhecimento matemático e o terceiro ao didático. Para isso, as autoras sugerem que, na sua formação, os futuros professores se envolvam na produção de justificações, sendo estas discutidas focando vários aspectos, tais

\footnotetext{
${ }^{1}$ Em língua portuguesa, o termo "demonstração" está associado a uma concepção mais formal, pelo que optamos pelo termo "justificação" que se aproxima mais do conceito de Stylianides (2007).
} 
como os modos de raciocínio e representação utilizados, bem como erros típicos dos alunos.

Stylianides e Stylianides (2009) se referem à existência de vários estudos que mostram que os futuros professores que lecionam para os primeiros anos têm predominantemente ideias erradas sobre a justificação, particularmente sobre o papel dos argumentos empíricos, em alguns casos, mesmo depois de terem tido formação sobre justificação. Também Lin et al. (2012b) afirmam que para muitos professores deste nível a sua convicção num resultado assenta mais na autoridade de entidades externas (como manuais ou colegas que reconhecem como mais competentes) do que no seu raciocínio, o que revela fraca autoconfiança na sua capacidade. Os autores concluem que são em número reduzido os estudos que procuram desenvolver o conhecimento dos professores e futuros professores nesta área, e resumem assim as suas orientações: resolver tarefas de justificação individualmente ou em pequenos grupos; realizar discussões coletivas; partilhar e criticar as justificações uns dos outros; promover desafios cognitivos e o estabelecimento de convicção nos resultados.

\section{Justificar generalizações em geometria: construindo um modelo de análise}

Para a análise dos dados, construímos um modelo sobre a justificação de generalizações em geometria procurando articular as ideias sobre o processo de justificar anteriormente revistas e o tópico matemático envolvido. Por um lado, o modelo deve captar em que medida a justificação apresentada pelos formandos cumpre o seu papel na sala de aula - convencer-se a si próprio e aos outros porque é verdadeira uma certa afirmação. Por outro lado, deve atender à sua validade, verificando se corresponde a um argumento ou conjunto de argumentos lógicos baseados em ideias previamente compreendidas e se a linguagem e o raciocínio apoiam a relação geral, mostrando que se aplica a todos os casos do domínio.

Atentando que o estudo incide sobre a justificação de generalizações para famílias de objetos geométricos, o quadro de análise atende à especificidade destes objetos e a natureza da atividade proposta, que se insere no âmbito do raciocínio geométrico. Nesse sentido, convocamos as ideias de Battista (2009) que afirma que operar mentalmente com objetos geométricos (por exemplo, compará-los, decompô-los e analisá-los) requer que estes tenham sido abstraídos a um nível suficientemente profundo. Para isso, há duas formas fundamentais de abstração em geometria - a estruturação espacial e a construção de modelos mentais:

A estruturação espacial é o ato mental de organizar um objeto ou um conjunto de objetos através da identificação das suas componentes e do estabelecimento de relações entre elas. Os modelos mentais são versões não verbais, versões mentais das situações que captam a estrutura das situações que representam (p. 94-95). 
Para o autor, o raciocínio envolve a ativação destes modelos mentais para que seja possível imaginar diferentes cenários e soluções para os problemas.

Desta forma, consideramos que a construção de justificações em geometria que permitam compreender a razão pela qual uma generalização é verdadeira é um processo que implica necessariamente a estruturação espacial dos objetos. Mais ainda, uma vez que uma justificação implica a explicitação de argumentos, é necessário ir além da dimensão mental a que se refere a estruturação espacial, entrando assim na estruturação geométrica que “descreve a estruturação espacial através de conceitos formais" (BATTISTA, 2007, p. 861). Isto significa que, ao estruturar geometricamente um objeto ou situação espacial, um indivíduo usa conceitos, tais como congruência, paralelismo, ângulo ou transformação geométrica para conceituar e operar sobre a situação. A estruturação geométrica assenta na estruturação espacial, pois sem se apoiarem em modelos mentais que captem a estrutura da situação, a estruturação geométrica não tem significado para o indivíduo.

Assim, o modelo de análise das justificações sobre generalizações (Quadro 1) foca-se, em primeiro lugar, na natureza dos argumentos produzidos no que diz respeito à incidência na estruturação geométrica (EG) dos objetos. Interessa-nos compreender em que medida os futuros professores investigam a razão pela qual as generalizações são válidas recorrendo à forma como os objetos estão estruturados, ou seja, de que forma se compõem e como se relacionam as suas componentes. Em segundo lugar, procuramos compreender se o raciocínio apoia a relação geral mostrando que se aplica em todos os casos desse domínio (LANNIN; ELLIS; ELLIOTT, 2011), pelo que estabelecemos indicadores que, por um lado, evidenciam a natureza dos argumentos usados e, por outro, identificam o grau de generalização da justificação. Adotamos a acepção de "exemplo genérico" de Balacheff (1988, p. 219) que “envolve tornar explícitas as razões da validade de uma afirmação através de operações ou transformações de um objeto que não é apresentado pelo seu valor próprio, mas como um representante característico da sua classe" sendo que "esta descrição envolve as propriedades e estruturas características da classe" (p. 219).

\begin{tabular}{|l|l|l|l|}
\hline \multirow{2}{*}{ Nível } & \multicolumn{3}{|c|}{ Descrição } \\
\cline { 2 - 4 } & $\begin{array}{l}\text { Natureza do } \\
\text { argumento }\end{array}$ & $\begin{array}{l}\text { Propriedades/procediment } \\
\text { os }\end{array}$ & Grau de generalização \\
\hline \multirow{2}{*}{ EG3 } & $\begin{array}{l}\text { Com base na correta } \\
\text { estruturação } \\
\text { geométrica da família } \\
\text { de figuras }\end{array}$ & $\begin{array}{l}\text { Explicita propriedades } \\
\text { relevantes e estabelecidas }\end{array}$ & $\begin{array}{l}\text { Usa uma linguagem genérica sobre a } \\
\text { família de figuras }\end{array}$ \\
\cline { 3 - 4 } & Incide sobre um exemplo genérico \\
\cline { 2 - 4 } & $\begin{array}{l}\text { Incide sobre uma ou mais figuras da } \\
\text { família sem generalizar }\end{array}$ \\
\hline
\end{tabular}




\begin{tabular}{|c|c|c|c|}
\hline \multirow{3}{*}{ EG2 } & \multirow{3}{*}{$\begin{array}{l}\text { Com base numa } \\
\text { estruturação } \\
\text { geométrica incompleta } \\
\text { da família de figuras }\end{array}$} & \multirow{3}{*}{$\begin{array}{l}\text { Explicita propriedades } \\
\text { relevantes e estabelecidas, } \\
\text { mas omite outras }\end{array}$} & $\begin{array}{l}\text { Usa uma linguagem genérica sobre a } \\
\text { família de figuras }\end{array}$ \\
\hline & & & Incide sobre um exemplo genérico \\
\hline & & & $\begin{array}{l}\text { Incide sobre uma ou mais figuras da } \\
\text { família sem generalizar }\end{array}$ \\
\hline \multirow{3}{*}{ EG1 } & \multirow{3}{*}{$\begin{array}{l}\text { Com base numa } \\
\text { estruturação } \\
\text { geométrica incorreta da } \\
\text { família de figuras }\end{array}$} & \multirow{3}{*}{$\begin{array}{l}\text { Explicita propriedades } \\
\text { irrelevantes, inexistentes ou } \\
\text { não estabelecidas }\end{array}$} & $\begin{array}{l}\text { Usa uma linguagem genérica sobre a } \\
\text { família de figuras }\end{array}$ \\
\hline & & & Incide sobre um exemplo genérico \\
\hline & & & $\begin{array}{l}\text { Incide sobre uma ou mais figuras da } \\
\text { família sem generalizar }\end{array}$ \\
\hline \multirow{3}{*}{ EG0 } & \multirow{3}{*}{$\begin{array}{l}\text { Sem recurso à } \\
\text { estruturação } \\
\text { geométrica da família } \\
\text { de figuras }\end{array}$} & $\begin{array}{l}\text { Explicita relações numéricas } \\
\text { sem relacionar com a } \\
\text { estruturação das figuras }\end{array}$ & $\begin{array}{l}\text { Incide sobre uma ou mais figuras da } \\
\text { família }\end{array}$ \\
\hline & & Testa a generalização & $\begin{array}{l}\text { Incide sobre uma ou mais figuras da } \\
\text { família }\end{array}$ \\
\hline & & $\begin{array}{l}\text { Recorre a uma fonte externa } \\
\text { de validação (por exemplo, o } \\
\text { GeoGebra, um colega ou um } \\
\text { manual) }\end{array}$ & Não se aplica \\
\hline
\end{tabular}

Quadro 1 - Quadro de análise dos níveis das justificações de generalizações

Fonte: Elaborado pelos autores (2018).

\section{Metodologia de investigação}

Este estudo tem um propósito interventivo, visando modificar as práticas da formação inicial de professores e educadores, de forma a melhorar as suas aprendizagens e contribuir para o conhecimento sobre a sua formação, partindo da compreensão que construímos sobre a forma como os futuros professores desenvolvem o seu raciocínio geométrico. A investigação foca-se na aprendizagem em contexto, a partir da concepção de estratégias e ferramentas de ensino, pelo que optamos pela metodologia de investigação baseada em design, na modalidade de experiência de formação (COBB et al., 2003; PONTE et al., 2016) em que a professora (a primeira autora do artigo) tem também o papel de investigadora. Esta modalidade de investigação é referida por Stylianides, Bieda e Morselli (2016, p. 344) como sendo uma "abordagem promissora na resposta às necessidades de desenvolvimento de formas eficazes para abordar as dificuldades de alunos e professores relativamente à argumentação e demonstração".

Os dados que apresentamos foram recolhidos durante o segundo ciclo do estudo, no ano letivo de 2014/15, envolvendo uma turma de 25 formandas que frequentavam a disciplina de Geometria ( $2^{\circ}$ ano da Licenciatura em Educação Básica ${ }^{2}$ ). No primeiro ciclo do estudo,

\footnotetext{
${ }^{2}$ Em Portugal, os futuros educadores de infância (dos 0 aos 5/6) anos e professores do $1 .^{\circ}$ ao $6 .^{\circ}$ ano (dos 6 aos 12 anos) começam por tirar uma licenciatura de três anos e depois um mestrado específico das áreas e dos anos em que vão ensinar. A disciplina tem uma duração de 15 semanas, implicando cerca de 67 horas em aula.
} 
realizado no ano anterior com outros formandos, verificamos que a justificação do raciocínio era um processo em que revelavam ideias erradas, tais como usar dados com base na percepção das figuras. Contudo, verificamos que as dificuldades eram particularmente sentidas quando se tratava de justificar uma generalização, o que nos levou a dedicar maior atenção a este aspecto.

Neste artigo, os dados dizem respeito a duas tarefas: a primeira, incidente em figuras do plano, foi realizada em grupos de 4 ou 5 elementos, tendo cada participante feito um registo individual que, em muitos casos, refletiu simultaneamente a discussão do grupo e particularidades do raciocínio da sua autora; a segunda, incidente em figuras do espaço, integrou o teste de avaliação final e individual.

A primeira tarefa, aplicada na quarta semana, diz respeito à soma de ângulos internos de um polígono. Anteriormente, as formandas construíram vários polígonos no GeoGebra e obtiveram os valores das somas das amplitudes dos ângulos internos $\left(180^{\circ}, 360^{\circ}, 540^{\circ} \ldots\right)$ a partir dos quais formularam uma generalização (obtendo várias expressões equivalentes e corretas). A tarefa que aqui apresentamos (Figura 1) tem como objetivo formular justificações para a generalização encontrada, já sem recurso ao software, correspondendo assim a uma tarefa de transição entre conjectura e justificação, de acordo com a classificação de Lin et al. (2012a), pois convida os alunos a justificarem conjecturas que os próprios estabeleceram.

Na tarefa "Relações entre ângulos" encontraste uma generalização para a soma dos ângulos internos de um polígono qualquer de $n$ lados. Vamos procurar justificá-la. Para isso, observa as três figuras seguintes. Todas elas partem do mesmo hexágono, no qual se iniciou uma estratégia possível para chegar à justificação procurada. Usa uma das figuras e completa a justificação recorrendo ainda a outras relações que já tenhas estabelecido.
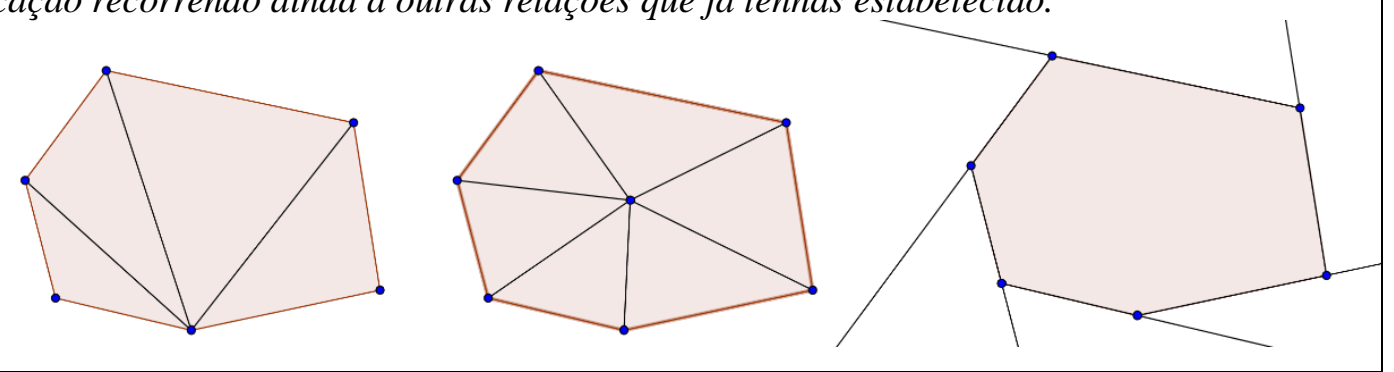

Figura 1 - Tarefa para justificação da soma de ângulos internos de um polígono Fonte: Elaborado pelos autores (2015).

Anteriormente, a justificação de afirmações já era solicitada, mas em situações em que eram fornecidos alguns valores numéricos (por exemplo, amplitudes de ângulos) e pedidos outros valores com base em propriedades estudadas. Na primeira tarefa sem valores específicos, realizada numa aula anterior, incidente na congruência entre ângulos 
verticalmente $\operatorname{opostos}^{3}$, registraram-se muitas dificuldades. Desta forma, a tarefa de justificação da generalização sobre a soma dos ângulos internos de um polígono de $n$ lados foi a primeira que envolveu uma família de figuras, uma vez que os hexágonos apresentados são tanto representantes de uma infinidade de hexágonos como representantes de um qualquer polígono de $n$ lados.

No que diz respeito à tarefa sobre a família de sólidos (Figura 2), inserida no teste final, pedia a generalização e justificação de relações entre alguns elementos (faces e vértices), o que as formandas já haviam realizado anteriormente para outras famílias, como prismas, pirâmides, antiprismas e alguns poliedros regulares e arquimedianos. Corresponde igualmente a uma tarefa de transição entre conjectura e justificação (LIN et al., 2012a).

No tempo que decorreu entre as duas tarefas aqui discutidas, a turma resolveu várias tarefas de justificação, mas, sobretudo, de transição entre conjectura e justificação que procuraram seguir os princípios de design referidos por Lin et al. (2012a). Entre esses princípios, destacamos o princípio relativo às normas de sala de aula que valorizam a partilha e discussão de ideias e que permitem encarar com naturalidade a apresentação de conjecturas, a sua aceitação ou rejeição. No que se refere estritamente às tarefas de justificação, foi dada especial atenção ao princípio sobre a classificação de afirmações matemáticas, incluindo o papel dos contraexemplos e a inadequação dos exemplos para validar uma generalização.

De uma maneira geral, o trabalho desenvolvido centrou-se nas dimensões saber justificar e compreender a natureza da justificação (LO; MCCRORY, 2009) e seguiu todas as orientações propostas por Lin et al. (2012b) anteriormente referidas. Além disso, o processo de justificar não foi ensinado como tópico independente, mas sim como processo de raciocínio abrangente e transversal e como uma forma de explicar ou compreender (STYLIANIDES; STYLIANIDES, 2009).

Na imagem estão representados três sólidos pertencentes a uma família de sólidos. Cada um destes sólidos é constituído por um prisma e duas pirâmides assentes em cada uma das bases do prisma. Se o prisma for triangular, as pirâmides também serão triangulares e assim sucessivamente para todos os sólidos.

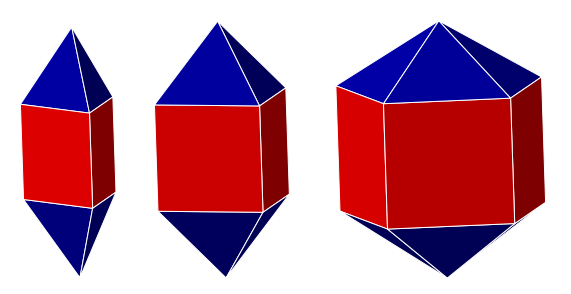

\footnotetext{
${ }^{3}$ A expressão "verticalmente opostos" significa, no Brasil, "ângulos opostos pelo vértice”.
} 
A. Encontra uma expressão para o número de faces do sólido, considerando que né o número de vértices da base do prisma. Justifica a expressão encontrada.

B. Encontra uma expressão para o número de vértices do sólido, considerando que néo número de vértices da base do prisma. Justifica a expressão encontrada.

Figura 2 - Tarefa para generalização e justificação do número de faces/vértices de uma família de poliedros Fonte: Elaborado pelos autores (2015).

A recolha de dados foi feita a partir dos registros de áudio e vídeo das aulas (para a primeira tarefa) e foi ainda realizada a análise documental das produções escritas. A análise de dados é feita a partir do modelo de análise apresentado no quadro 1.

\section{Resultados}

\subsection{Justificação da generalização para a soma das amplitudes dos ângulos internos de um polígono}

Nesta tarefa, as formandas trabalharam em grupos, mas cada uma fez o seu registro que, na maioria das vezes, correspondeu à resolução que foi discutida no grupo.

A fase inicial de trabalho não foi fácil, pois, tal como na justificação da congruência de ângulos verticalmente opostos, nas figuras não constam quaisquer valores e algumas formandas pensaram que para chegarem à soma dos ângulos internos do polígono precisariam do valor de cada ângulo. Uma das formandas chegou a perguntar se não poderiam usar a medida $90^{\circ}$ para um ângulo interno que parecia mesmo ser reto. A professora frisou então que deveriam prosseguir as estratégias iniciadas e que, para saber a soma, não precisamos de conhecer cada parcela. Progressivamente, os grupos foram avançando na atividade pretendida.

De seguida, apresentamos resoluções que ilustram o trabalho desenvolvido pelos grupos.

O primeiro hexágono está dividido em 4 triângulos. Todos os vértices de cada triângulo cobrem todos os ângulos internos do polígono. Se soubermos que a soma dos ângulos internos de um triângulo é igual a $180^{\circ}$, basta multiplicarmos 180 por 4 (4 triângulos) e conseguimos obter a amplitude de todo o polígono. A expressão que generaliza é $(n-2) \times 180$.

Se um polígono tiver 10 lados, é possível desenhar 8 triângulos; se tiver 6 lados, desenhamos 4 triângulos. Se tiver $n$ lados, desenhamos $n$-2 triângulos.

(Áudio da resolução de Célia da tarefa sobre a soma dos ângulos internos de um polígono, 16/03/2015).

A resposta de Célia parte da estratégia sugerida pela primeira figura. Baseia-se na correta estruturação geométrica da família de figuras, pois identifica duas propriedades relevantes e já estabelecidas - a soma das amplitudes dos ângulos internos de um triângulo e a possibilidade de decompor o polígono em $n$-2 triângulos cujos ângulos compõem os ângulos 
do polígono original. Célia usa o hexágono e ainda o decágono com a clara intenção de os tratar como exemplos genéricos, pois explicita propriedades que todos os elementos da classe possuem. Desta forma, podemos considerar que a sua justificação corresponde ao nível EG3.

Todos os grupos usaram a primeira figura para justificar a generalização, mas a maioria resolveu seguir também as outras estratégias. A resposta seguinte (Figura 3) pertence a Anita e é representativa do seu grupo. Note-se, porém, que a utilização da terceira figura surge a partir da discussão no seio do grupo enquanto Teresa explica a sua ideia às colegas:

Teresa: Estes todos dão $180^{\circ}$ [os ângulos formados por cada ângulo interno juntamente com o externo]. Então $6 \times 180$. Mas os externos não queremos, estão a mais. Mas os externos todos juntos dão 360! Portanto, vamos ao $6 \times 180$ e tiramos os 360 !

(Áudio do diálogo no grupo de Teresa, 16/03/2015)
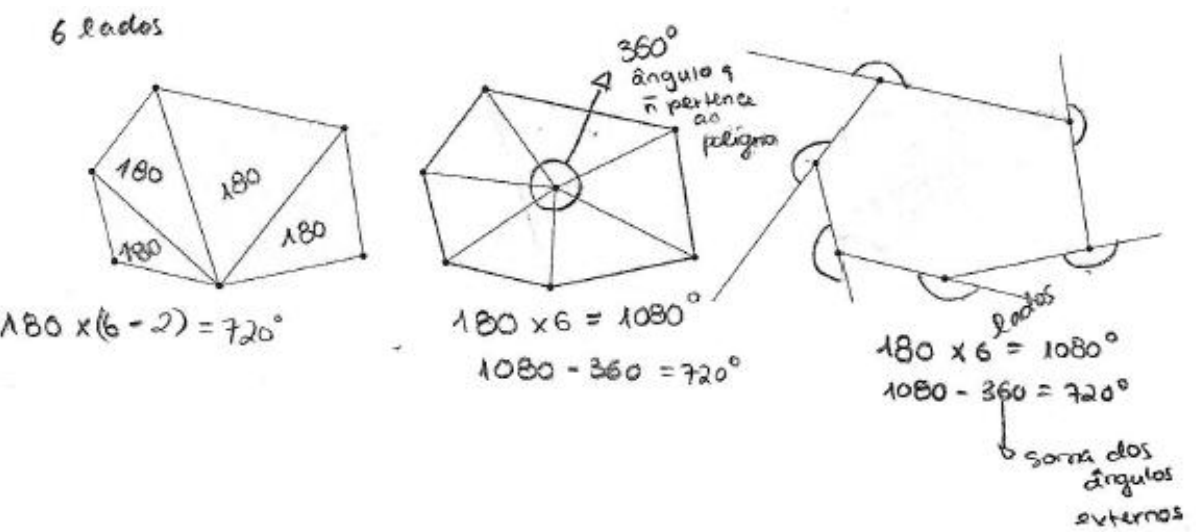

Sabendo que a soma dos ângulos internos de um triângulo é $180^{\circ}$, conseguimos descobrir a soma dos ângulos internos do polígono. Neste caso, conseguimos dividir este polígono em 4 triângulos, ou seja, se multiplicarmos 180 por 4 obtemos a soma dos ângulos internos do polígono.

Figura 3 - Resolução de Anita da tarefa sobre a soma dos ângulos internos de um polígono Fonte: Reprodução da resolução pelos autores (2015).

A resposta do grupo de Anita apoia-se numa correta estruturação geométrica, explicitando propriedades relevantes já estabelecidas (soma dos ângulos internos de um triângulo, o ângulo de $360^{\circ}$ formado na segunda figura, a soma dos ângulos externos de um polígono e a relação entre um ângulo externo e um interno), sem explicar a relação entre o número de lados do polígono e o número de triângulos em que é decomposto. Fica implícito que a composição dos ângulos dos triângulos gera todos os ângulos do hexágono, uma relação que só é abordada para a figura central, onde o ângulo de $360^{\circ}$ não é um ângulo do hexágono. Assim, a justificação apresentada explicita as propriedades mais relevantes, mas omite outras, pelo que lhe atribuímos o nível EG2. Quanto ao grau de generalização, estas propriedades incidem apenas no caso do hexágono que não é tratado como exemplo genérico (o número de triângulos da decomposição é variável para a classe). 
Outra resposta (Figura 4) pertence a um grupo que propôs a expressão $360+180(n-4)$ como generalização. Esta expressão não se relaciona diretamente com nenhuma das figuras apresentadas, pelo que as formandas usam outras expressões. A justificação de Isabel é, sobretudo, uma interpretação das expressões encontradas e não elabora um texto que articule as várias ideias. Contudo, o seu registro revela claramente que os seus argumentos se baseiam na estruturação geométrica, pois explicita quase todas as propriedades que são relevantes, omitindo a relação numérica entre o número de lados do polígono e o número de triângulos em que é decomposto e a sua justificação.

\begin{tabular}{|c|}
\hline 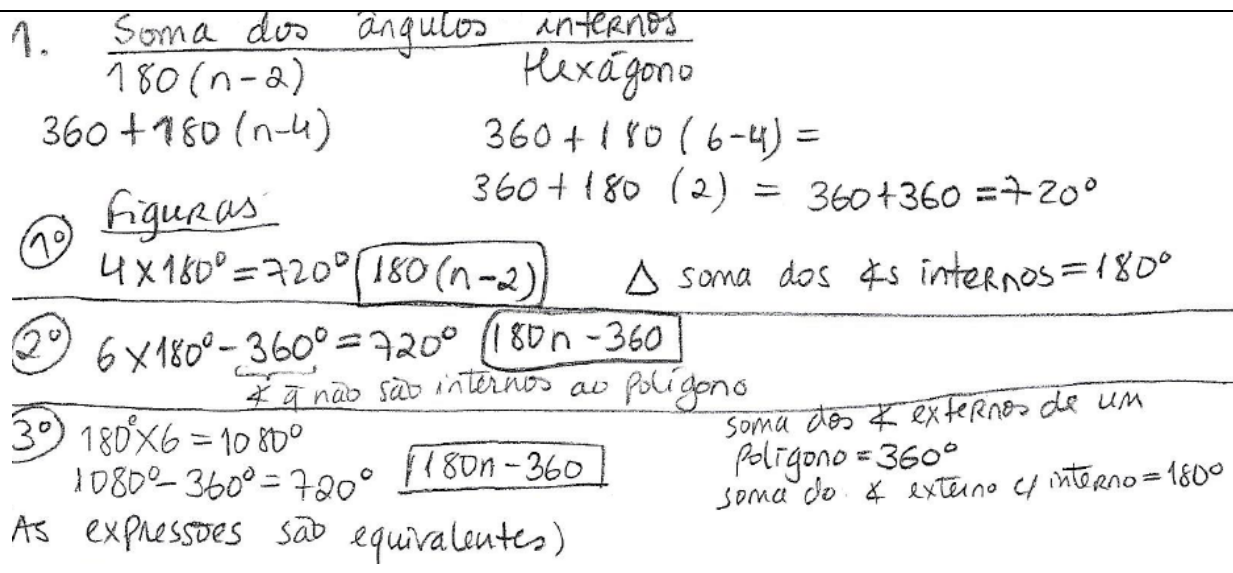 \\
\hline
\end{tabular}

Figura 4 - Resolução de Isabel da tarefa sobre a soma dos ângulos internos de um polígono Fonte: Reprodução da resolução pelos autores (2015).

Nesta resposta, o hexágono é usado como um exemplo que ilustra e explica as expressões utilizadas, mas não há uma explicação no sentido de o tornar claramente num exemplo genérico, apesar de a formanda explicitar as propriedades comuns à classe. Esse aspecto foi abordado pela professora junto do grupo:

Profa: Sim, mas esse caso será para o hexágono. E se tivermos outros polígonos? Por exemplo, com 10 lados?

Isabel: Fazemos... 8 triângulos. Tiramos dois aos lados.

Prof $^{\mathrm{a}}:$ E então?

Isabel: Exato. Então dá $(n-2) \times 180$ !

Andreia: E para o outro [figura do meio] fazemos $6 \times 180$ e tiramos depois dois triângulos. $2 \times 180$.

Prof $^{\mathrm{a}}$ : E porque é que tiras os ângulos de dois triângulos?

Isabel: Pois... Isso és tu a forçar para dar igual...

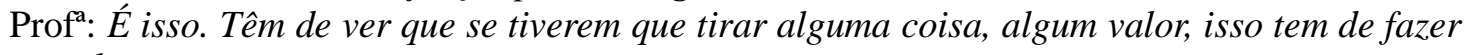
sentido...

(Diálogo no grupo entre a professora e duas formandas, 16/03/2015)

Este diálogo mostra que as formandas estavam conscientes da relação entre o número de lados do polígono e o número de triângulos da decomposição (para o caso da primeira figura), mas não o explicitaram no seu registo. 
Pelas razões indicadas, consideramos que esta justificação corresponde ao nível EG2, com uma linguagem que incide apenas sobre uma das figuras da família. Além disso, salientamos que este grupo parece querer corresponder ao desafio da professora de dar sentido às expressões utilizadas, o que corresponde a uma visão da justificação como explicação do porquê. Este aspecto é perceptível no seu registo, mas particularmente no discurso de Isabel, quando diz que tirar dois triângulos é "forçar para dar igual".

\subsection{Justificação de generalizações sobre relações entre elementos de uma família de poliedros}

A tarefa sobre a família de poliedros (Figura 2) integrou o teste de avaliação individual da turma realizado na última semana de aulas. Foram propostas duas versões, ambas incidentes numa família infinita de $\operatorname{sólidos}^{4}$ : a versão A incide sobre o número de faces e a versão B sobre o número de vértices. Ao contrário da tarefa sobre a soma de ângulos internos de polígonos, as formandas não conheciam a expressão geral para o número de faces/vértices dos sólidos que era também pedida.

No caso desta tarefa, uma vez que foi realizada individualmente, apresentamos os dados quantitativos relativos ao tipo de justificações apresentadas (Tabela 1). Estes dados mostram que, das 25 formandas que realizaram o teste, 19 (76\%) apresentaram generalizações corretas, mas as suas justificações são de diferente tipo.

Tabela 1 - Distribuição dos níveis das justificações de generalizações

\begin{tabular}{llllcc}
\hline Nível & EG3 & EG2 & EG1 & EG0 & $\begin{array}{c}\text { Generalização } \\
\text { errada }\end{array}$ \\
& & & Usa relações numéricas & Testa a expressão &
\end{tabular}

\begin{tabular}{ccccccc}
\hline Freq. Absol. & 3 & 8 & 1 & 3 & 4 & 6 \\
\hline$\%$ & 12 & 32 & 4 & 12 & 16 & 24 \\
\hline \multicolumn{7}{c}{ Fonte: Elaborado pelos autores (2018). }
\end{tabular}

De seguida, apresentamos e analisamos justificações que se restringem às generalizações corretas e que ilustram diferentes tipos de raciocínio. Começamos pela resposta de Júlia (Figura 5) sobre o número de faces da família (questão A) que apresenta uma justificação que consideramos completamente correta. Esta formanda estrutura cada sólido como a junção de três sólidos que já conhece e explicita propriedades relevantes e estabelecidas anteriormente, como o número de faces laterais ser o mesmo que o número de

\footnotetext{
${ }^{4}$ Esta família de sólidos foi adaptada das bipirâmides alongadas, uma subclasse dos sólidos de Jonhson com três sólidos apenas. Para estes sólidos retiramos a restrição de que todas as faces sejam polígonos regulares.
} 
vértices da base, quer nas pirâmides, quer nos prismas. Júlia é das poucas participantes que explicita que as faces destes sólidos correspondem apenas às faces laterais dos prismas e das pirâmides que os compõem, por via da junção das suas bases. Note-se ainda que o seu discurso não é específico de casos particulares da família, aplicando-se a todos os sólidos. Desta forma, consideramos que Júlia apresenta uma justificação de nível EG3, usando uma linguagem genérica sobre a família de sólidos.

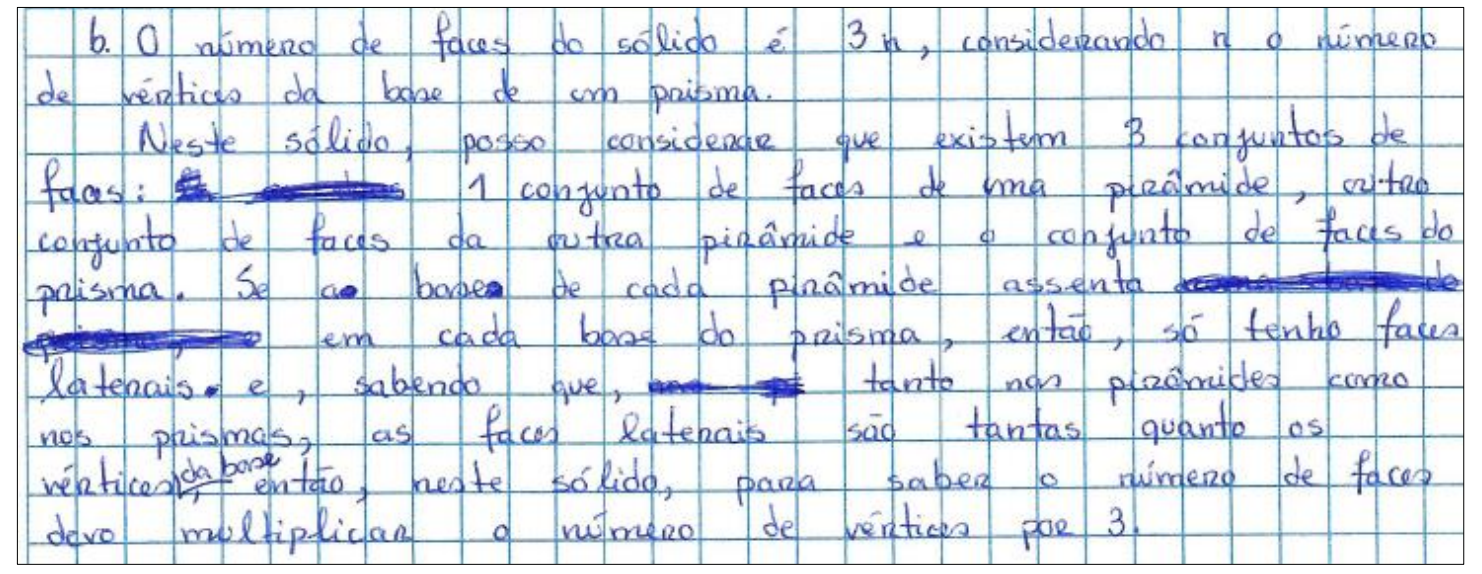

Figura 5 - Resolução de Júlia da tarefa sobre o número de faces da família de sólidos Fonte: Reprodução da resolução pelos autores (2015).

Analisemos agora a resolução de Lúcia (Figura 6) sobre o número de vértices desta família (questão B). A formanda faz uma correspondência dos vértices do sólido aos vértices das pirâmides, o que está correto, pois todos os vértices destas são vértices do sólido. Contudo, deveria explicitar a razão pela qual os vértices dos prismas já foram contemplados por esta contagem, ou seja, explicita propriedades relevantes, mas omite outras. Assim, consideramos que Lúcia apresenta uma resposta de nível EG2 e, tal como Júlia, o seu discurso é genérico relativamente à família de sólidos.

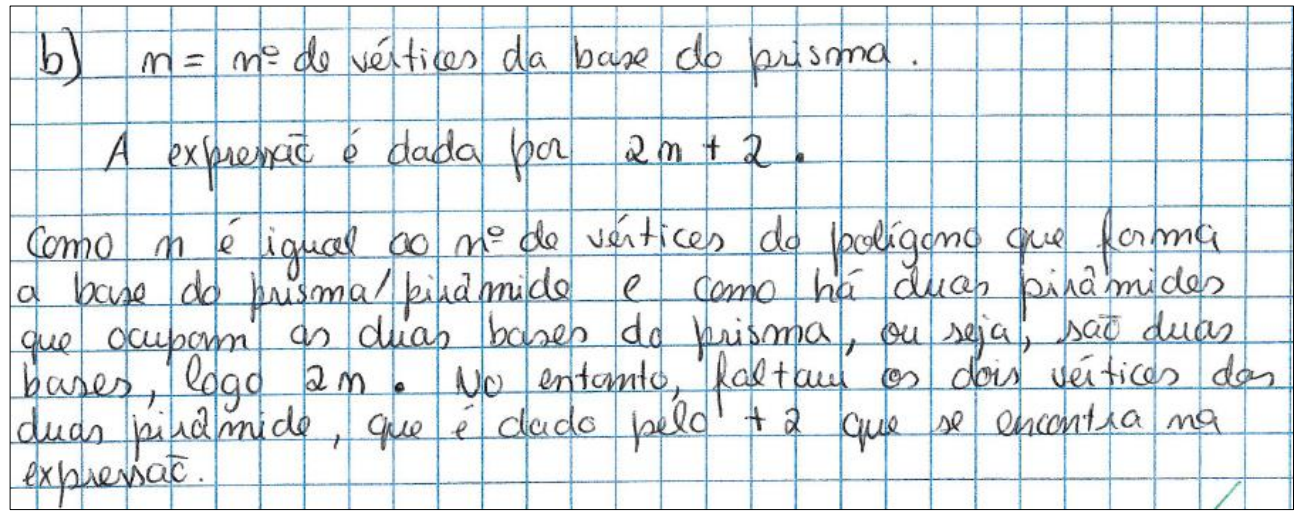

Figura 6 - Resolução de Lúcia da tarefa sobre o número de vértices da família de sólidos Fonte: Reprodução da resolução pelos autores (2015).

Teresa apresenta uma generalização sobre o número de faces das bipirâmides (questão A) composta por duas partes: a primeira, ao indicar a expressão com uma justificação dos 
seus parâmetros e, em particular, da razão pela qual surge o valor 3 (porque é constituído por 3 sólidos sobrepostos); a segunda, ao testar a expressão para dois casos, assumindo que a segunda figura tem uma base quadrangular e a terceira hexagonal (Figura 7).

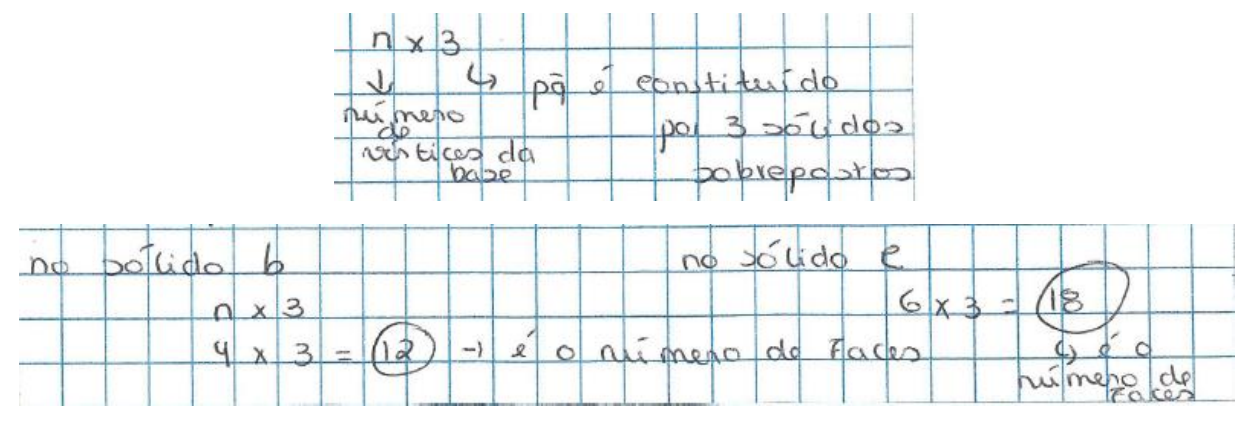

Figura 7 - Resolução de Teresa da tarefa sobre o número de faces da família de sólidos Fonte: Reprodução da resolução pelos autores (2015).

A resposta de Teresa parece indicar que estrutura espacialmente as bipirâmides como a junção de três sólidos, o que está correto. No entanto, esta propriedade é irrelevante se não tivermos em consideração que o número de faces que contamos em cada um dos três sólidos é o mesmo. Teresa testa ainda a sua expressão, possivelmente para lhe atribuir uma maior fiabilidade. Desta forma, atribuímos dois níveis à justificação que apresenta: o nível EG2, correspondente a uma justificação baseada numa estruturação geométrica incompleta e onde usa uma linguagem genérica sobre a família de figuras, e o nível EG0, por via da justificação com base em testes. Esta duplicação dos níveis significa que a formanda parece ter uma ideia que a sua justificação deve integrar a forma como o sólido se encontra estruturado, mas considera a sua argumentação insuficiente e reforça-a com testes à generalização.

A estratégia de realizar testes à conjectura foi utilizada por outras formandas, como Iva (Figura 8). A formanda justifica a sua generalização aplicando-a à primeira figura apresentada na tarefa e explicando que, por contagem, se verifica que o valor obtido (9) coincide com o resultado da expressão. Refere ainda que o número de faces para os outros sólidos cumpre a expressão. Desta forma, a formanda não faz referência às propriedades dos sólidos, apenas justifica a sua conjectura com um teste, pelo que atribuímos o nível EG0 à sua justificação.

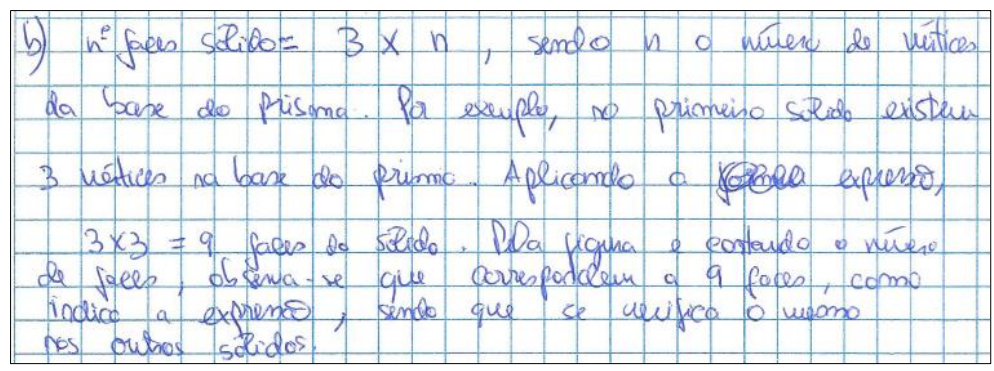

Figura 8 - Resolução de Iva da tarefa sobre o número de faces da família de sólidos Fonte: Reprodução da resolução pelos autores (2015). 
Finalmente, consideremos a resolução de Cristina (Figura 9). Ao contrário das respostas anteriores, a formanda apresenta a generalização apenas no fim da sua resposta. Aparentemente, a sua justificação acaba por corresponder ao processo pelo qual a formanda chega à generalização - a partir das relações numéricas que identifica entre o número de vértices e o número de faces em três sólidos da família, sem qualquer referência a propriedades geométricas. Desta forma, Cristina apresenta uma justificação à qual atribuímos o nível EG0.

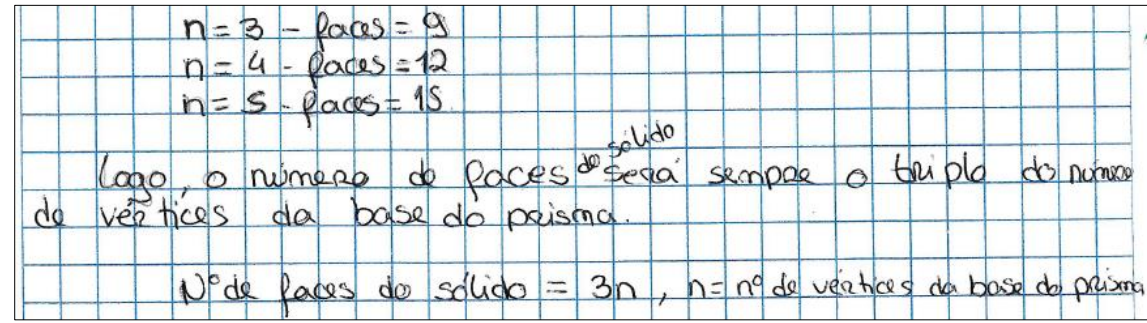

Figura 9 - Resolução de Cristina da tarefa sobre o número de faces da família de sólidos Fonte: Reprodução da resolução pelos autores (2015).

Sintetizando, as respostas desta tarefa individual mostram que apenas cerca de $40 \%$ das formandas deram uma justificação completa ou quase completa recorrendo à estruturação geométrica (não consideramos neste grupo a resposta de Teresa que só apresenta uma propriedade). Os casos em que atribuímos o nível EG2 correspondem a respostas em que o modelo mental da família de figuras é claramente correto, mas as formandas acabam por omitir alguma(s) propriedade(s) que até podem ter tido em conta, mas não as explicitam, o que torna a justificação incompleta. Um aspecto curioso diz respeito às justificações que se apoiam nas regularidades numéricas e que são todas referentes à questão sobre o número de faces, cuja expressão é $3 n$, e não sobre o número de vértices, cuja expressão é $2 n+2$. Embora o número de respostas não seja muito expressivo, podemos conjecturar que as generalizações que correspondem a regularidades numéricas mais facilmente reconhecíveis (como é o caso dos múltiplos de 3) sugerem uma abordagem à justificação com base nessa regularidade, talvez por ser mais acessível ou por ser a forma como as formandas chegaram à expressão.

\section{Discussão}

Os resultados obtidos na tarefa sobre a soma dos ângulos internos de um polígono mostram que as formandas estavam ainda no início da aprendizagem sobre a justificação de generalizações, o que se manifestou sobretudo em dois momentos: no momento inicial, em que revelaram dificuldades por não serem apresentados quaisquer valores; no momento do 
registro, em que mostraram dificuldades ou resistência em construir um discurso argumentativo, baseado nas propriedades das figuras. Além disto, é ainda de sublinhar a tendência para referir apenas o caso do hexágono que apenas algumas resoluções tratam como exemplo genérico. Assim, esta tarefa revelou dificuldades relacionadas com dois fatores: a natureza da afirmação a justificar - uma generalização - que se apoia numa representação genérica (referente a uma família de figuras em vez de uma figura única) em que não surgem quaisquer valores; os princípios de uma justificação, nomeadamente a necessidade de explicitar adequadamente os argumentos, usando uma linguagem geral que se aplica a mais do que um caso particular (LANNIN; ELLIS; ELLIOTT, 2011). Isto significa que as formandas revelaram dificuldades quer sobre saber justificar, quer sobre compreender a natureza da justificação (LO; MCCRORY, 2009).

Contudo, esta tarefa revelou também aspectos positivos. O seu enunciado permite investigar o porquê através do confronto e mobilização de diferentes representações e propriedades, o que conduziu a discussões sobre o significado das generalizações. Não houve qualquer sinal de que a resolução da tarefa estabelecesse a validade das generalizações que as formandas nunca colocaram em causa, pelo que a justificação ficou claramente associada à compreensão da razão da sua validade. Outro aspecto positivo a assinalar é que todas as resoluções envolvem uma correta estruturação geométrica da família de figuras, pelo que as justificações são válidas ou contêm argumentos válidos e pertinentes, mesmo que incompletas.

A tarefa sobre as relações entre elementos da família de poliedros revelou alguns aspectos comuns, mas outros significativamente diferentes. No que diz respeito às dificuldades, à exceção das três participantes que não resolveram a tarefa (por motivos que desconhecemos), as resoluções não se fixam tanto na análise de um exemplo particular, havendo várias respostas que usam uma linguagem genérica sobre a família de figuras. Contudo, 28\% das participantes não recorrem à estruturação geométrica, usando como argumentos o teste da expressão numérica ou a identificação de regularidades numéricas. De novo, estes problemas dizem respeito à dimensão compreender a natureza da justificação (LO; MCCRORY, 2009), mas de uma forma diferente. Quanto à dimensão saber justificar, algumas formandas conseguem mostrar a validade da generalização, através da construção de uma argumentação completa ou quase completa, baseada em propriedades relevantes e estabelecidas.

Assim, no que diz respeito ao tipo de argumentos usados pelas participantes para justificar generalizações, há uma diferença entre as duas tarefas. Na tarefa sobre os polígonos, 
todas as resoluções recorrem à estruturação geométrica das figuras através de propriedades relevantes e estabelecidas, embora o grau de generalização seja tendencialmente reduzido. $\mathrm{Na}$ tarefa dos poliedros, há uma parte considerável de formandas que não recorre à estruturação geométrica, realizando antes testes ou explicitando uma regularidade numérica, o que pode ter sido favorecido pela simplicidade e familiaridade com a sequência (os múltiplos de três).

A comparação dos desempenhos nas duas tarefas apresentadas leva-nos a considerar também a diferença entre a sua formulação e o contexto em que foram resolvidas. Por um lado, o fato de todas as justificações da tarefa dos polígonos recorrerem à estruturação geométrica pode ter sido promovido pelas estratégias já iniciadas no próprio enunciado, algo que não aconteceu com a tarefa dos poliedros. Também o fato de ter sido resolvida em pequenos grupos gerou interação entre as formandas e entre estas e a professora que, como percebemos pelos diálogos, podem conduzir a um questionamento que favorece a compreensão do porquê de a afirmação ser válida. Por outro lado, na tarefa dos poliedros existem três representações de elementos da família, ao contrário do único hexágono presente na primeira tarefa, o que pode ter promovido um raciocínio mais abrangente, em vez de se focar num único caso. Finalmente, o fato de ser a última tarefa e ser realizada num contexto avaliativo pode ter favorecido uma construção da justificação mais cuidada, com atenção à melhor explicitação dos argumentos.

\section{Conclusão}

No que diz respeito à natureza dos argumentos usados, a perspectiva de justificar para compreender o porquê da validade de uma afirmação pareceu bem integrada pelas participantes que, na maioria dos casos, se basearam em propriedades relevantes e já estabelecidas, envolvendo uma correta estruturação geométrica, que resultaram em justificações válidas ou contendo argumentos válidos e pertinentes. Quanto a dificuldades, identificamos os seguintes fatores: a natureza da afirmação a justificar que se apoia numa representação genérica; os princípios de uma justificação, nomeadamente a explicitação dos argumentos; tendência para argumentar com base em regularidades numéricas, ou seja, sem recurso à estruturação geométrica, nos casos em que a generalização está associada a uma sequência simples.

No que diz respeito às atividades que promovem o saber justificar e compreender a natureza da justificação, o fato de o enunciado sugerir a justificação recorrendo a raciocínios diferentes, parece apoiar a utilização de argumentos com base na estruturação geométrica. Por 
outro lado, a representação no enunciado de vários elementos da família de figuras, pode promover uma linguagem mais geral, em vez de se focar em casos particulares. Finalmente, a valorização da partilha e discussão de ideias, conduz a um questionamento que favorece a compreensão do porquê de a afirmação ser válida.

Podemos assim afirmar que a experiência realizada mostra a necessidade de reforçar o trabalho quer na dimensão saber justificar, quer na dimensão compreender a natureza da justificação (LO; MCCRORY, 2009). Em particular, é necessário vencer a resistência em construir um discurso argumentativo, que observamos em resoluções que se reduzem à interpretação esquemática de expressões ou representações visuais, de forma a valorizar a dimensão comunicativa deste processo (YACKEL; HANNA, 2003).

É também importante elevar o grau de generalidade do discurso que, em alguns casos, é demasiadamente apoiado em exemplos particulares e não evidencia que a generalização se aplica a todo o domínio de figuras, um requisito da justificação (LANNIN; ELLIS; ELLIOTT, 2011). Na verdade, existe uma linha pouco definida entre apresentar um exemplo genérico que seja representativo do domínio - uma estratégia apropriada para justificar - e apoiar a justificação em exemplos que valem apenas por si próprios - o que corresponde a um erro associado a uma concepção errada comum sobre o papel dos resultados empíricos na validade de uma justificação (STYLIANIDES; STYLIANIDES, 2009).

Consideramos ainda importante insistir no papel da justificação enquanto ferramenta que permite compreender o porquê (HAREL; SOWDER, 2007; LANNIN; ELLIS; ELLIOTT, 2011; STYLIANIDES; BIEDA; MORSELLI, 2016) e, consequentemente, perceber que a realização de testes ou outros processos que não se baseiem nas propriedades das figuras não estabelecem a validade nem cumprem tal papel. Finalmente, este estudo sugere ainda que o desenho de tarefas que promovam a produção e confronto de diferentes justificações e representações, num ambiente de interação entre pares, é um elemento determinante no desenvolvimento da capacidade de justificar.

\section{Agradecimentos}

O presente artigo foi realizado no âmbito do projeto $\mathrm{O}$ raciocínio geométrico e a visualização espacial na formação inicial de professores dos primeiros anos sedeado no Centro Interdisciplinar de Estudos Educacionais - referência ESEXL/IPL-CIED/2016/A12.

\section{Referências}


BALACHEFF, N. Aspects of proof in pupils' practice of school mathematics. In: PIMM, D. (Ed.).

Mathematics, teachers and children. London, UK: Hodder \& Stoughton, 1988. p. 216-238.

BATTISTA, M. T. The development of geometric and spatial thinking. In: LESTER, F.K. (Ed.). Second handbook of research on mathematics teaching and learning. Greenwich, CT: Information Age, 2007. p. 843-908.

BATTISTA, M. T. Highlights of research on learning school geometry. In: CRAINE, T.V.; R. RUBENSTEIN (Eds.). Understanding geometry for a changing world. Reston, VA: NCTM, 2009. p. 91-108.

COBB, P. et al. Design experiments in educational research. Educational Researcher, Washington, DC, v. 32, n. 1, p. 9-13, 2003.

HANNA, G. Proof, explanation, and exploration: An overview. Educational Studies in Mathematics, Dordrecht, Holanda, n. 44, p. 5-23, 2000.

HAREL, G.; SOWDER, L. Toward comprehensive perspectives on the learning and teaching of proof. In: LESTER, F.K. (Ed.). Second handbook of research on mathematics teaching and learning. Greenwich, CT: Information Age, 2007. p. 805-842.

LANNIN, J. K.; ELLIS, A. B; ELLIOTT, R. Developing essential understanding of mathematical reasoning for teaching mathematics in prekindergarten-grade 8. Reston, VA: National Council of Teachers of Mathematics, 2011.

LIN, F. L. et al. Principles of task design for conjecturing and proving. In: G. HANNA, G.; DE VILLIERS, M. (Eds.). Proof and proving in mathematics education, new ICMI study series 15. Dordrecht, Holanda: Springer, 2012a. p. 305-325.

LIN, F. L. et al. Teachers' professional learning of teaching proof and proving. In: G. HANNA, G.; DE VILLIERS, M. (Eds.). Proof and proving in mathematics education, new ICMI study series 15. Dordrecht, Holanda: Springer, 2012b. p. 327-346.

LO, J.; MCCRORY, R. Proof and proving in mathematics for prospective elementary teachers. In: LIN, F. L. et al. (Eds.). ICMI Study 19: Proof and proving in mathematics education. Taipei, Taiwan: Department of Mathematics, National Taiwan Normal University, 2009. v. 2, p. 41-46.

NATIONAL COUNCIL OF TEACHERS OF MATHEMATICS. Princípios e Normas para a Matemática Escolar. Lisboa: APM, 2007.

PONTE, J. P. et al. Investigação baseada em design para compreender e melhorar as práticas educativas. Quadrante, Lisboa, v. 25, n. 2, p. 77-98, 2016.

PONTE, J. P.; MATA-PEREIRA, J.; HENRIQUES, A. O raciocínio matemático nos alunos do ensino básico e do ensino superior. Praxis Educativa, Ponta Grossa, v. 7, n. 2, p. 355-377, jul./dez. 2012.

PONTE, J. P. et al. Programa de Matemática do ensino básico. Lisboa: Ministério da Educação/Direção Geral da Inovação e Desenvolvimento Curricular, 2007.

STYLIANIDES, A. J. Proof and proving in school mathematics. Journal for Research in Mathematics Education, Reston, VA, n. 38, p. 289-321, 2007.

STYLIANIDES, A. J., BIEDA, K. N.; MORSELLI, F. Proof and argumentation in mathematics education research. In: GUTIÉRREZ, A.; LEDER, G. C.; BOERO, P. (Eds.). The second handbook of research on the psychology of mathematics education. Rotherham, Holanda: Sense. 2016. p. 
315-351.

STYLIANIDES, G. J.; STYLIANIDES, A. J. Facilitating the transition from empirical arguments to proof. Journal for Research in Mathematics Education, Reston, VA, n. 40, p. 314-352, 2009.

YACKEL, E.; HANNA, G. Reasoning and proof. In KILPATRICK, J.; MARTIN, W. G.; SCHIFTER, D. (Eds.). A research companion to principles and standards for school mathematics. Reston, VA: National Council of Teachers of Mathematics, 2003. p. 22-44

Submetido em 08 de Janeiro de 2018. Aprovado em 12 de Junho de 2018. 